\title{
Mineração
}

\section{A mineração de areia industrial na Região Sul do Brasil}

\author{
Gilda Carneiro Ferreira \\ Docente do Departamento de Geologia Aplicada/UNESP/IGCE/Rio Claro \\ E-mail: gildacf@rc.unesp.br \\ Elias Carneiro Daitx \\ Docente do Departamento de Geologia Aplicada/UNESP/IGCE/Rio Claro
}

\section{Resumo}

$\mathrm{Na}$ Região Sul do Brasil existem atualmente dez empresas de mineração produzindo areia industrial a partir do beneficiamento de areia quartzosa, de quartzito e de arenito, utilizando processos de seleção granulométrica e mineralógica e agregando valor a esses bens minerais. O Estado de Santa Catarina é o maior produtor de areia industrial da Região Sul, com destaque para a região de Araquari, onde são lavrados sedimentos quaternários litorâneos, abastecendo principalmente a maior fundição da América Latina, localizada em Joinville. As minas situadas nos Estados do Paraná, em Campo Largo, e do Rio Grande do Sul, em Viamão, abastecem com prioridade as indústrias de cerâmica e de vidro, respectivamente. Esse expressivo mercado consumidor tem atraído a atenção da maior mineradora de areia industrial do país, com jazidas situadas em São Paulo, a qual tem buscado alternativas para a instalação de novas minas nos Estados do Paraná e de Santa Catarina.

Palavras-chave: areia industrial, mineração, mercado produtor.

\begin{abstract}
In the south of Brazil, ten mining companies produce industrial sand by processing quartzite sand composed of quartz and sandstone. Granulometric and mineralogical methods are used which enhance the value of these minerals. The State of Santa Catarina is the largest producer of industrial sand in the southern region, where they mine coast sediments from Quaternary. Most production is in the Araguari area. The state boasts the largest foundry in Latin América, located in Joinville. Campo Largo, State of Parana, and Viamão, State of Rio Grande do Sul, are primary suppliers for the ceramic and glass industries. This significant consumer market has attracted the attention of the country's largest industrial sand mining company, with mineral areas in the State of São Paulo, which is considering alternative installation of new mines in Paraná and Santa Catarina States.
\end{abstract}

Keywords: industrial sand, mining, producer market. 


\section{Introdução}

O estudo do mercado produtor de areia industrial na Região Sul foi realizado por meio de consultas junto ao Departamento Nacional da Produção Mineral - DNPM, para identificar as áreas produtoras desse bem mineral nos Estados do Paraná, de Santa Catarina e do Rio Grande do Sul, seguido de visitas técnicas às empresas de mineração e trabalhos de campo nas áreas com depósitos conhecidos (Ferreira \& Daitx, 2000 a).

Esses levantamentos indicaram a existência, nessa região, de dez empresas mineradoras de areia industrial com produção significativa para o setor e outras seis com atividades de lavra paralisadas ou não iniciadas. No Estado do Paraná, essas empresas desenvolvem suas atividades principalmente nos municípios de Campo Largo (3) e em Lapa (1); em Santa Catarina as empresas mineradoras de areia atuam nos municípios de Araquari (2), Jaguaruna (1) e Imbituba (2); e no Rio Grande do Sul opera apenas uma empresa, localizada no município de Viamão (Figura 1).

Em Santa Catarina foram produzidas aproximadamente 265.000 toneladas de areia industrial no ano de 2.000 , correspondendo a quase $80 \%$ de toda a produção da Região Sul do país (DNPM, 2001). Do total apresentado anteriormente, cerca de $75 \%$ são destinados às indústrias de fundição, particularmente aquelas situadas no município de Joinville e região.

O total de áreas com portarias de lavra para areia industrial na Região Sul alcança a 30, embora alguns depósitos com autorização de lavra para areia de construção civil produzam igualmente areias beneficiadas, utilizadas nas indústrias de argamassa ou fundição e poderiam, portanto, ser consideradas como jazidas de areia industrial.

A Mineração Jundu S/A, maior produtora de areia industrial do país, com produção em torno de 2.500.000 t/ano, atualmente com áreas em lavra nos municípios de Descalvado e Analândia (SP), vem desde 1997 pesquisando areia industrial no Paraná, para poder suprir o abastecimento de alguns clientes da Região Sul e, também, para abastecer novas indústrias de vidro que estão se instalando nos municípios de Balsa Nova (PR) e Barra Velha (SC).

Em 1999, a empresa Sibelco Mineração Ltda. adquiriu Portarias de Lavra na região sul e áreas com processos em fase de requerimento de lavra, ou pesquisa para areia industrial, e instalou uma nova usina de beneficiamento em Jaguaruna (SC), com o objetivo de abastecer a indústria cerâmica e, futuramente, as grandes fundições do Estado ou empresas produtoras de vidro plano que ali viessem a operar. A sua capacidade de competir nesses últimos mercados é uma das principais incógnitas do setor.

\section{Beneficiamento da areia}

O termo areia industrial é aqui definido como "... material de granulometria variada, composto essencialmente de sílica e que passou por um processo de beneficiamento..." (Ferreira \& Daitx, 2000 b). As fontes para a produção desse bem mineral na área em estudo são representadas por depósitos de areia quartzosa, arenito ou quartzito.

Entre as diversas etapas de produção de areias industriais, a do beneficiamento é, provavelmente, a mais importante. Numa visão geral, qualquer corpo arenoso pode ser transformado em areia industrial, cujas características estarão implicitamente ligadas às do próprio depósito original, mas o que determinará o seu aproveitamento será, fundamentalmente, a economicidade dos produtos a serem obtidos após o seu beneficiamento.

Excetuadas questões ligadas ao posicionamento geográfico do mercado consumidor - e, conseqüentemente, sua relação com o mercado produtor -, a própria visão da prospecção de um depósito arenoso para fins de produção de areia industrial está diretamente subordinada à visão do seu futuro beneficiamento e baseia-se em parâmetros indicadores da ocorrência de um "pré-beneficiamento natural". Entre esses parâmetros detacam-se: corpos arenosos pré-enriquecidos por processos geológicos (depósi- tos eólicos, fluviais, com zonas "lixiviadas"), distribuição granulométrica que permita a obtenção de diversas frações, grãos com características intrínsecas adequadas (resistência, arredondamento, etc.), baixo teor em impurezas ou das frações sem aproveitamento econômico (rejeito), cor do material após lavagem, friabilidade do material, dimensionamento e exposição em superfície, etc.

Diversos desses condicionantes estão presentes nas jazidas estudadas, em intensidades diferentes, e, juntamente com fatores inerentes ao mercado consumidor suprido pelas empresas produtoras, influenciam diretamente os processos de beneficiamento empregados na produção dos seus diversos tipos de areias industriais.

Em linhas gerais, o beneficiamento do material arenoso visa à retirada de impurezas e de frações sem utilização econômica e a classificação das areias em várias faixas granulométricas adequadas às suas diversas aplicações industriais; representa, em síntese, um processo de seleção granulométrica e mineralógica. O principal material a ser separado corresponde à fração síltico-argilosa, indesejável por representar ou uma fonte de contaminação de alumínio, ferro e álcalis, na fabricação de vidros especiais e de produtos químicos, ou um material indesejável na produção de moldes de fundição. Essa fração síltico-argilosa, que pode representar até $20 \%$ do minério, é descartada em lagoas de decantação, por não possuir ainda um aproveitamento econômico, e representa um dos principais problemas ambientais em todas as minerações de areia industrial (Ferreira,1995).

As impurezas estão representadas por minerais pesados (zircão, ilmenita, magnetita, turmalina, cianita, estaurolita, sillimanita), hidróxidos de ferro e/ou manganês e grãos de feldspato, prejudiciais particularmente na produção de vidro, por introduzirem contaminantes na mistura (ferro, manganês, titânio) ou se constituírem em pontos refratários na etapa de fusão da matéria-prima.

As unidades de beneficiamento de areias existentes nas minerações visita- 


\section{Legenda}

Sedimentos litorâneos (TQ)

$\checkmark v$ Formaçäo Serra Geral e coberturas

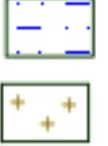

Sedimentos da Bacia do Paraná

Embasamento cristalino (unidades pré-cambrianas e eocambrianas)
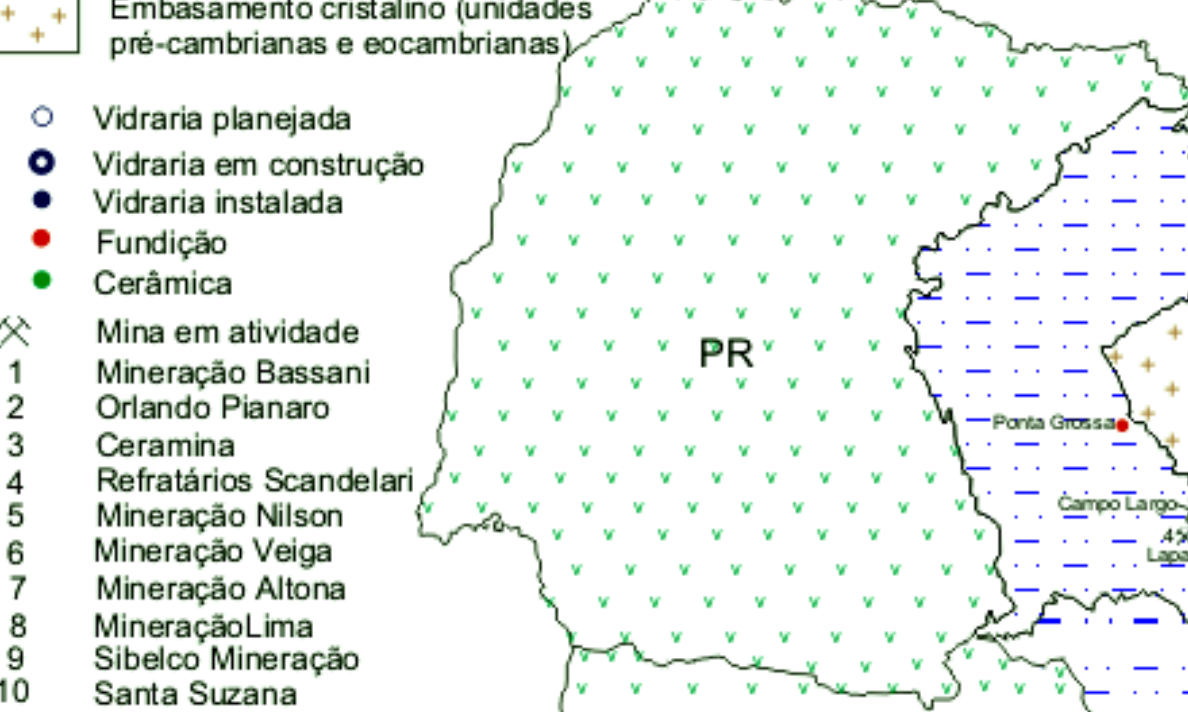

- Vidraria instalada

- Fundiçäo

Cerâmica

Ceramina

Refratários Scandelari

MineraçäoLima

Santa Suzana

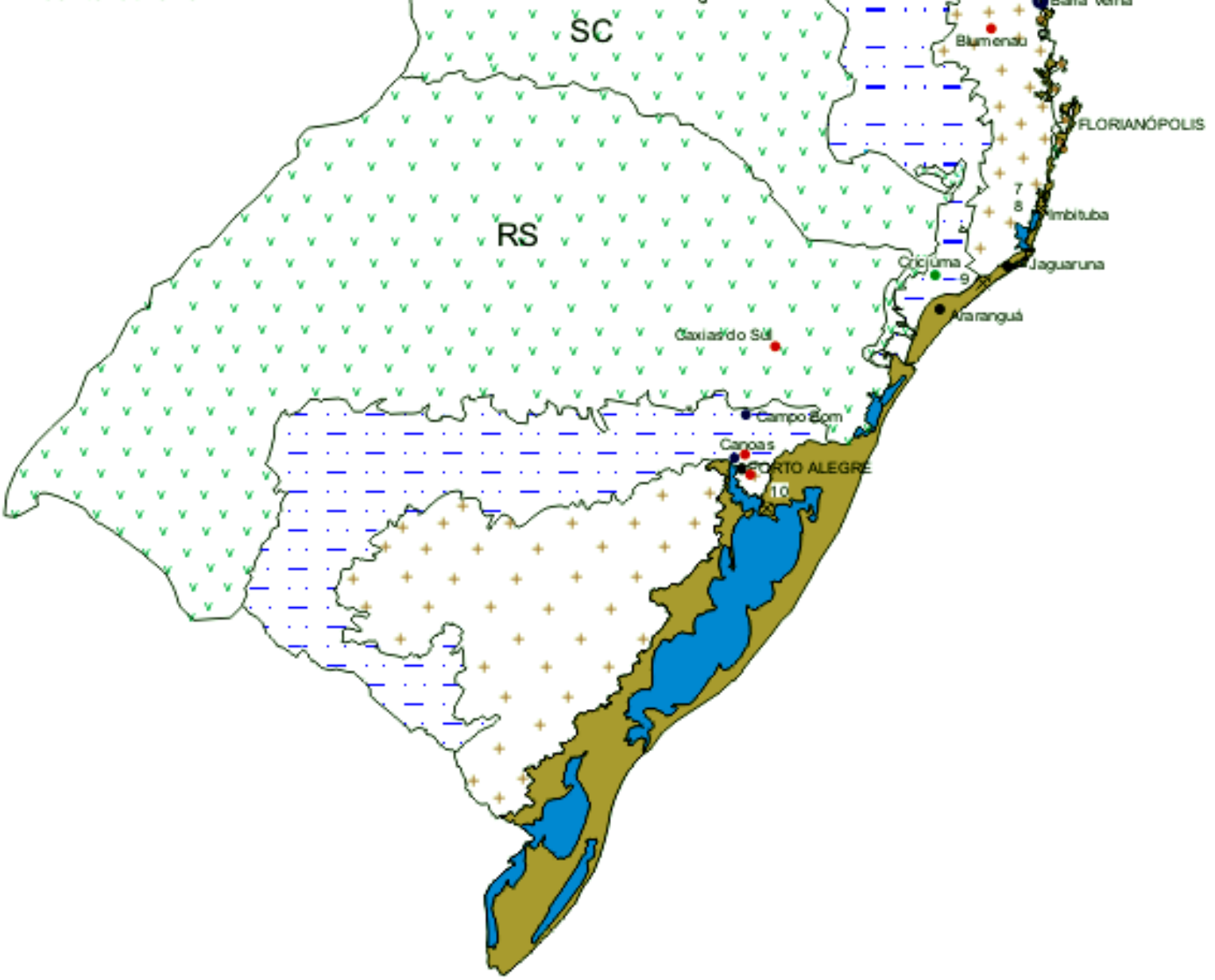

Figura 1 - Principais produtores e consumidores de areia industrial na Região Sul. 
das operam com esquemas semelhantes em relação à produção de areia industrial para uso em fundições, vidros coloridos, ou para argamassa, diferindo, face às diferentes escalas de trabalho, na quantidade e no arranjo dos diversos equipamentos básicos (peneiras, lavadores, hidrociclones classificadores, cones desaguadores, etc.).

\section{Principais produtores na Região Sul}

A Região Sul, no ano de 2000, produziu cerca de $34310^{3} \mathrm{t}$ de areia industrial, incluindo a produção de quartzito industrial, distribuídas nos Estados com os seguintes valores: Santa Catarina 264.000 t; Rio Grande do Sul - 74.000 t; Paraná - 5.000 t (DNPM, 2001).

As principais empresas mineradoras de areia industrial, na Região Sul, encontram-se localizadas no Estado de Santa Catarina, nos municípios de Araquari, Jaguaruna e Imbituba. Existem, contudo, diversas outras empresas mineradoras detentoras de importantes reservas de areia industrial, particularmente no entorno da região de Araquari, mas ainda sem atuação no mercado produtor de areia industrial. Toda a areia industrial produzida nesse Estado é proveniente de sedimentos arenosos inconsolidados litorâneos.

No Paraná, a produção de areia industrial concentra-se no município de Campo Largo e provém principalmente da lavra de quartzitos friáveis, gerando um material de granulação fina, que, após beneficiamento, apresenta as características de areia industrial, com amplo uso na indústria cerâmica local e de outros Estados. Os trabalhos de pesquisa desenvolvidos pela empresa Mineração Jundu S/A, no município de Ponta Grossa, no ano de 2000, bloquearam reservas aprovadas de areia industrial na ordem de 1,5 $\mathrm{M} \mathrm{t}$, provenientes de arenitos da Formação Furnas, podendo essa região se transformar numa nova área produtora desse bem mineral no Estado do Paraná.

No Rio Grande do Sul, a produção de areia industrial, para uso na indústria de vidro, concentra-se no município de
Viamão; pequenas empresas localizadas no litoral norte do Estado produzem areia para fundição em pequena escala e não foram incluídas nesse estudo.

As areias industriais produzidas na Região Sul são utilizadas principalmente na indústria de fundição; uma parcela pequena da produção abastece as indústrias de vidro, cerâmica e argamassa da região. A areia industrial produzida no Paraná supre há vários anos diversas indústrias regionais, inclusive cerâmicas do Estado de São Paulo, localizadas principalmente em Pedreira e Jundiaí.

\section{1 Áreas produtoras do Estado do Paraná}

No município de Campo Largo (PR), localizado cerca de $30 \mathrm{~km}$ de Curitiba, estão instaladas as principais empresas de mineração de areia industrial do Estado, com reservas da ordem de $92 \mathrm{M}$ t e produzindo anualmente cerca de $5.000 \mathrm{t}$ de areia industrial (DNPM, 2001).

A Mineração Bassani Ltda. atua nesse município desde 1988, produzindo areia industrial a partir de quartzitos friáveis, de granulação fina, bem classificados, de coloração branca, creme ou rosa-clara. Essa areia é usada na fabricação de louças e porcelanas de alta qualidade, suprindo as indústrias cerâmicas de Pedreira (SP) e de Campo Largo (PR), na produção de louças e fritas, respectivamente. A lavra do minério é feita a céu aberto, em bancadas, semimecanizada, com desmonte e o carregamento do minério na frente de lavra é feito manualmente e com carregamento do minério em caminhões, do pátio de estocagem para venda, sendo feito por carregadeira (Figura 2). O teor de $\mathrm{SiO}_{2}$ é superior a $97 \%$.

A empresa Orlando Pianaro está instalada na região de Campo Largo, produzindo areia industrial para a indústria cerâmica e de construção civil, proveniente de quartzitos de grã fina, decompostos e intercalados em xistos. As areias produzidas por essa empresa apresentam teor médio de $\mathrm{SiO}_{2}$ da ordem de $98,5 \%$. A lavra é feita a céu aberto, em bancadas, sendo o minério desmontado mecanicamente por uma pá-carregadeira
(Figura 3). Na área existem peneiras, sendo o único processo de beneficiamento do bem mineral.

A empresa Ceramina - Indústria Cerâmica e Mineração Ltda., instalada em Guabiroba, município de Campo Largo, produz areia industrial proveniente de um quartzito branco-acinzentado, friável, de granulação fina a média. A empresa abastece exclusivamente a Porcela Schmidt S/A com areias apresentando teor de $\mathrm{SiO}_{2}$ superior a $97 \%$.

No município de Lapa, as reservas de areia industrial alcançam 0,7 M t e nele se encontra a área de lavra da empresa Refratários Scandelari Ltda., que produz areia industrial a partir do beneficiamento (britagem, moagem e classificação) de arenito. Essa empresa abastece pequenas fundições localizadas no Paraná e em Santa Catarina, fornecendo tijolos e massas refratárias.

\section{2 Áreas produtoras do Estado de Santa Catarina}

Os depósitos arenosos da região de Araquari, posicionada na porção nordeste do Estado, se distribuem pelos municípios de Araquari, São Francisco do Sul e Barra do Sul; no primeiro deles, se localizam duas importantes minerações produtoras de areia industrial no Estado de Santa Catarina.

O município de Araquari é o principal produtor do Estado e se destaca pela produção de areia industrial proveniente de sedimentos quaternários litorâneos (Martin et al., 1988). Individualmente, as reservas de areia no município alcançam a $58 \mathrm{M}$ t e são as maiores do Estado; somadas essas reservas às dos demais municípios da região de Araquari, as reservas totais de areia industrial dessa região atingem 114,8 M t (DNPM, 2001), tornando-a o maior pólo potencial para produção de areia em todo o Estado de Santa Catarina. Atualmente, a produção de areia industrial do município alcança aproximadamente 200.000 t/ano.

A principal empresa produtora do Estado, Mineração Veiga Ltda., instalouse em Araquari em 1993 e produz areia para fundição, sendo a maior produtora 
de areia industrial da Região Sul. Abastece principalmente as indústrias de fundição de Joinville (SC), destacando-se a Tupy Fundições Ltda., maior da América Latina. A principal areia produzida por essa empresa apresenta teores de $\mathrm{SiO}_{2}$ em torno de 99,6\%, 0,1\% de argila e módulo de finura 55 AFS. Produz também, como subproduto do beneficiamento, areia utilizada na construção civil e para a fabricação de argamassa. A lavra do minério é feita a céu aberto, em bancadas, mecanicamente, utilizando-se retroescavadeira para a retirada do minério e caminhões basculantes para o transporte até o beneficiamento. Para a retirada da cobertura vegetal e do capeamento, é utilizado trator de esteira e pá-carregadeira. Quando a extração do minério alcança o nível freático, são utilizadas dragas para se fazer a lavra do minério. $\mathrm{Na}$ área da empresa existe uma usina de beneficiamento, onde o minério é lavado e classificado mecanicamente (Figura 4), quando necessário, as areias são secas em fornos a óleo.

A Mineração Nilson Ltda. iniciou sua produção de areia industrial nesse município no ano de 1998, produzindo atualmente areias industriais para abastecer as indústrias de fundição na região de Joinville e Jaraguá do Sul. As areias produzidas por essa empresa apresentam teor de $\mathrm{SiO}_{2}$ superior a $99,6 \%$, teor de argila variando de $0,04 \%$ a $0,25 \%$ e módulo de finura de 50 AFS a 95 AFS. Cerca de $10 \%$ de sua produção é representada por areias com alto teor de $\mathrm{Fe}_{2} \mathrm{O}_{3}$ e argila, sendo comercializadas para a construção civil. A lavra é feita a céu aberto, mecanicamente, em tiras, devido à espessura do minério (em média de 1,0 m). Da frente de lavra, o minério segue de caminhão até a usina de beneficiamento, onde é lavado, classificado mecanicamente e, às vezes, guardado em silos. Dependendo da utilização, as areias são secas em fornos a óleo.

No município de Imbituba, na região sudeste do Estado, é produzido areia industrial a partir da lavra de sedimentos arenosos de dunas móveis, com duas empresas de mineração atuando na região. As reservas de areia industrial no município situam-se na ordem de $2 \mathrm{M}$ t (DNPM, 2001). A produção de areia nesse município é da ordem de 20.000 t/ ano.

A Mineração Altona Ltda. possui reservas de areia industrial em Benedito Novo e Imbituba, concentrando suas atividades nesse último município. Produz areia para fundição, abastecendo exclusivamente a Eletro Aço Altona S/ A, localizada em Blumenau (SC), empresa do mesmo grupo. As areias dessa jazida apresentam teores em torno de $99,68 \%$ de $\mathrm{SiO}_{2}$ e $0,17 \%$ de argila e módulo de finura variando entre 63 AFS e 84 AFS. A lavra é feita pelo desmonte de dunas móveis, com o auxílio de pá-carregadeira (Figura 5), com transporte por caminhões até Blumenau, onde passa por uma secagem.

A Mineração Lima Ltda. extrai também areia de dunas, representando sua jazida a extensão da anterior, sendo formada por areia quartzosa com $99,6 \%$ de $\mathrm{SiO}_{2}$ em média. A lavra é semelhante à da Mineração Altona Ltda., onde a extração da areia das dunas é feita por pácarregadeira e o transporte por caminhões basculantes (Figura 6) e, na área de lavra, parte do minério é peneirado e seco em forno a óleo. Produz areia seca grossa, areia seca de fundição e areia fina úmida, abastecendo principalmente o mercado de construção civil, sendo uma pequena parcela destinada às indústrias de fundição.

A região das jazidas de areia de Jaguaruna, englobando os municípios de Jaguaruna, Araranguá, Urussanga e Pedras Grande, na porção sul do Estado, é um tradicional produtor de areia industrial e possui reservas da ordem de 13,5 M t(DNPM, 2001). A areia industrial produzida nessa região é proveniente da lavra de sedimentos quaternários litorâneos (Caruso Jr., 1995) de uma única empresa de mineração. No ano de 1999, foram produzidas aproximadamente 20.000 t/ano de areia industrial.

A Sibelco Mineração Ltda. se instalou no município de Jaguaruna em 1999, onde montou uma unidade de beneficiamento com capacidade instalada de 20.000 t/mês para atender as indústrias cerâmicas e de fundição do Estado. Adquiriu os direitos de lavra da Cominas -
Mineradora Conventos S/A na região e possui atualmente seis áreas com concessão de lavra, nos municípios de Jaguaruna e Araranguá. A lavra da areia é feita a céu aberto, mecanicamente, em bancadas; após a extração o minério é transportado por caminhões para o beneficiamento, onde ocorre a lavagem e classificação mecânica do minério. Conforme a sua utilização, passa posteriormente por processos de secagem em fornos a óleo ou a gás e por um processo de moagem. Após beneficiadas, as areias industriais apresentam teor de $\mathrm{SiO}_{2}$ superior a $99,5 \%$ e módulo de finura de 57 AFS. Esse bem mineral abastece principalmente as indústrias cerâmicas da região de Criciúma.

\section{3 Áreas produtoras do Estado do Rio Grande do Sul}

A região areeira de Viamão engloba os municípios de Viamão e Tapes, na extremidade sul da Região Metropolitana de Porto Alegre, e nela se situam as principais reservas desse bem mineral no Rio Grande do Sul, da ordem de $8 \mathrm{M} \mathrm{t}$ (DNPM, 2001).

Nesse Estado, a empresa Santa Suzana Mineração Ltda., atualmente incorporada à Mineração Jundu S/A, é a única de porte atuando na produção de areia industrial, com o objetivo principal de abastecer as duas indústrias de vidro pertencentes ao Grupo Saint Gobain, do qual faz parte, localizadas nos municípios de Campo Bom e Canoas (RS); parte da produção é vendida para pequenas indústrias de fundição.

Possui reservas nos municípios de Viamão e Tapes, atuando neste primeiro município desde 1986, onde produz aproximadamente 50.000 t/ano de areia industrial, a partir de sedimentos arenosos inconsolidados. A lavra do minério é feita a céu aberto, mecanicamente, em bancadas e através de dragagem, em grandes cavas com 4 a 5 metros de profundidade, de onde o minério é retirado através de bombeamento. Os sedimentos arenosos são beneficiados por meio de processos mecânicos de lavagem e classificação em peneiras estáticas e vibratórias, cones classificadores, deslamadores, e classi- 


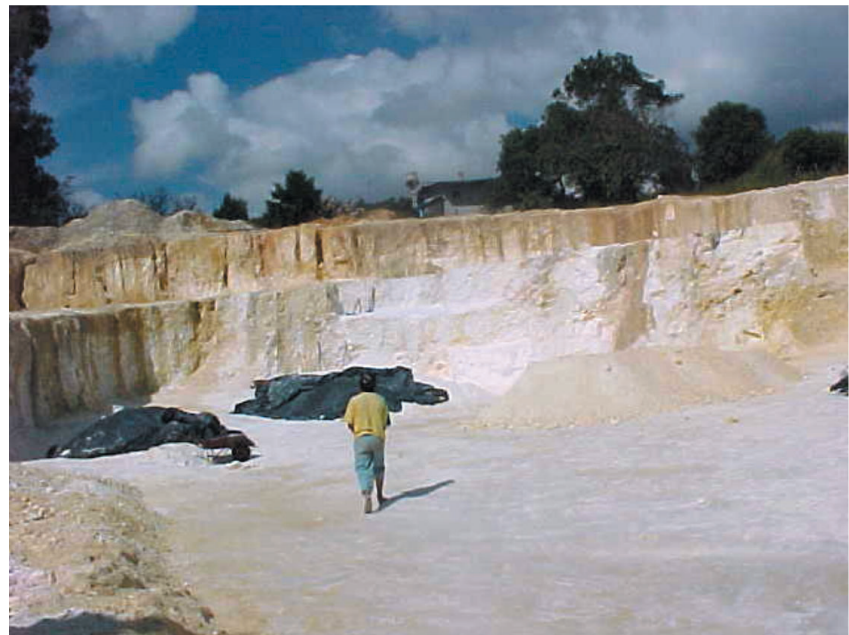

Figura 2 - Vista geral dos depósitos da Mineração Bassani, em Campo Largo (PR), expondo os bancos arenosos.

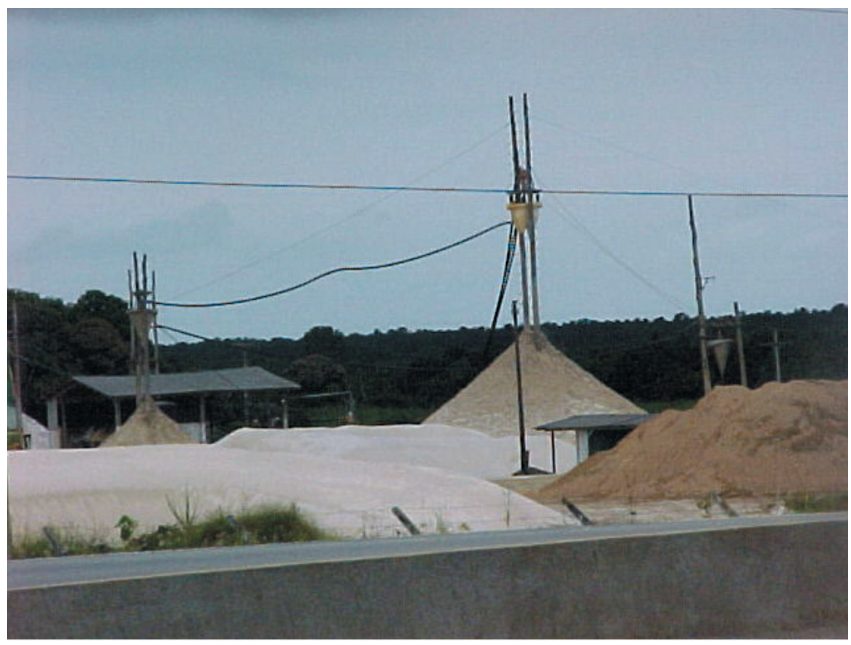

Figura 4 - Instalações de beneficiamento de areia industrial da Mineração Veiga Ltda. Local: Araquari (SC).

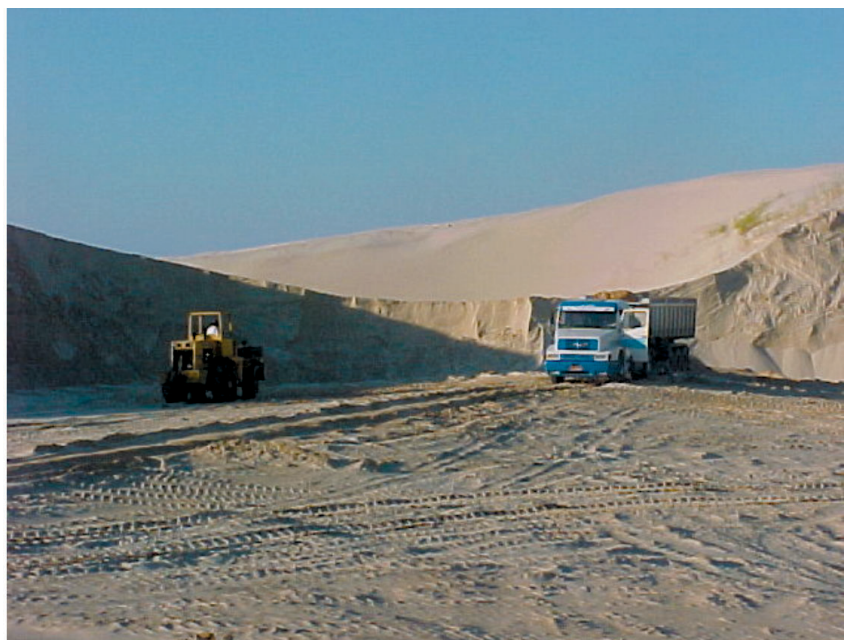

Figura 6 - Frente de lavra da areia de dunas da Mineração Lima Ltda. Local: Imbituba (SC).

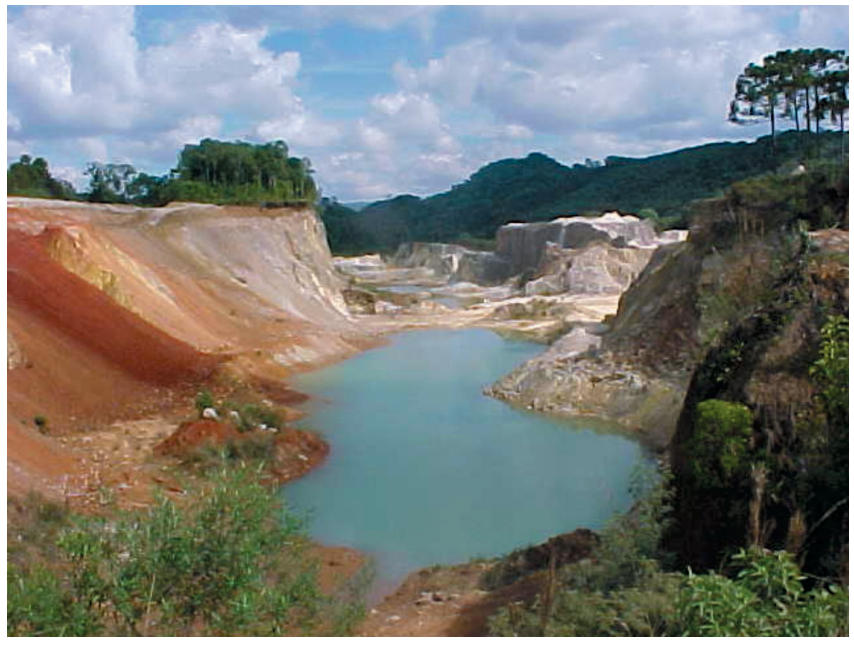

Figura 3 - Vista geral da área da mineração Orlando Pianaro FI. Local: Campo Largo (PR).

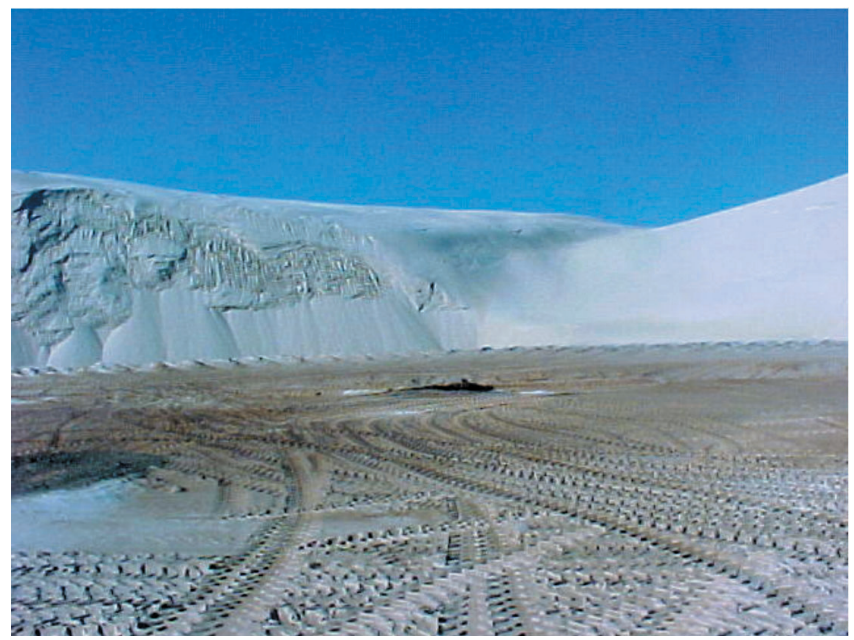

Figura 5 - Frente de lavra da areia de dunas da Mineração Altona Ltda. Local: Imbituba (SC).

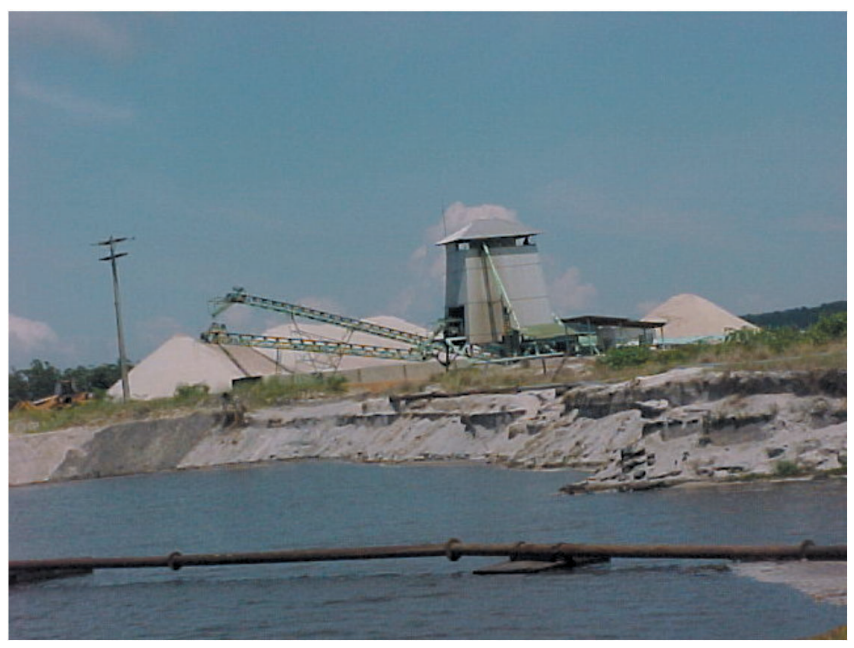

Figura 7 - Vista geral da Usina de beneficiamento da Santa Suzana Mineração Ltda., vendo-se ao fundo pilhas de minério já beneficiado. Local: Viamão (RS). 
ficador espiral (Figura 7). A areia lavada apresenta teor de $\mathrm{SiO}_{2}$ em torno de $99,7 \%$.

Diversas outras pequenas minerações atuam no litoral norte do Estado produzindo areia industrial, utilizadas por fundições localizadas na porção central do Estado.

\section{Conclusões}

Existem atualmente na Região Sul do Brasil dez empresas de mineração de areia industrial, produzindo cerca de $343 \times 10^{3}$ t/ano. Dessas empresas, quatro se localizam no Estado do Paraná, cinco em Santa Catarina e uma no Rio Grande do Sul. As reservas de areias industriais da Região Sul superam a 200 M t, o que garante o abastecimento do mercado por mais de uma centena de anos, levandose em consideração a produção atual de areia industrial na região e um crescimento no consumo devido à instalação de duas novas fábricas de vidro plano na Região Sul.

Nos Estados de Santa Catarina e Rio Grande do Sul, os depósitos de areia industrial correspondem, em sua grande maioria, a sedimentos quaternários litorâneos, representados principalmente por paleodunas. No Estado do Paraná são explorados, para a produção de areia industrial, corpos de quartzito e arenito, com idades proterozóica e paleozóica. Há pesquisas em desenvolvimento visando ao aproveitamento econômico dos arenitos da Formação Furnas para a produção futura de areia industrial.

A maior empresa de mineração de areia industrial da Região Sul, Mineração Veiga Ltda., localiza-se no Estado de Santa Catarina e é responsável por apro- ximadamente $55 \%$ da produção da Região Sul e $70 \%$ da produção do Estado. As areias produzidas por essa empresa abastecem principalmente a Tupy Fundições Ltda., maior fundição da América Latina, que consome cerca de 150.000 t/ ano de areia industrial.

O restante da produção sulina de areia industrial $(45 \%)$ está pulverizado nas outras nove empresas, com produção variando de 2.000 t a 50.000 t/ano. As areias produzidas por essas empresas, a partir de processos simples de beneficiamento, ou mesmo sem serem tratadas, abastecem principalmente pequenas e médias fundições, indústrias cerâmicas, indústrias de argamassa, indústria de vidro e diversas outras indústrias de transformação, incluindo, esporadicamente, a indústria de cimento.

A maior empresa de mineração de areia industrial do Estado de São Paulo, Mineração Jundu S/A, tem demonstrado interesse em instalar uma unidade produtora na Região Sul e já pesquisou reservas de sedimentos arenosos adequados à produção de areia industrial, na região de Ponta Grossa (PR), além de buscar outras alternativas para abastecer parte dos mercados consumidores dos Estados do Paraná e de Santa Catarina, principalmente as indústrias de vidro plano ora em instalação nesses Estados.

A entrada da empresa Sibelco Mineração Ltda. na produção de areia industrial no Estado de Santa Catarina, em 1999, representou o principal evento desse setor nos últimos anos. Por se tratar de uma empresa de grande porte, detentora de processos de beneficiamento modernos, o que lhe garante qualidade nas areias produzidas, e experiência de pro- dução em larga escala, sua atuação futura poderá modificar o quadro de produtores vigente atualmente e apresentado nesse estudo.

\section{Agradecimentos}

Os autores agradecem à FAPESP Fundação de Amparo à Pesquisa do Estado de São Paulo, processo 98/13371-5, pelo financiamento dos trabalhos dessa pesquisa.

\section{Referências Bibliográficas}

CARUSO Jr., F. Mapa geológico e de recursos minerais do sudeste de Santa Catarina. Brasília: DNPM, 1995. 52p (Programa Cartas de Síntese e Estudos de Integração Geológica), mapa, escala 1:100.000.

DNPM - DEPARTAMENTO NACIONAL DA PRODUÇÃO MINERAL. Anuário Mineral Brasileiro. Brasília: DNPM, 2001. v.30, 404p.

FERREIRA, G.C. Estudo dos mercados produtor e consumidor de areia industrial no Estado de São Paulo. Rio Claro: Instituto de Geociências e Ciências Exatas, Universidade Estadual Paulista, 1995. 142 p. (Tese de Doutorado em Geociências).

FERREIRA, G.C., DAITX, E.C. Estudo dos mercados produtor e consumidor de areia industrial na Região Sul do Brasil. São Paulo: FAPESP, 2000 a. 59p. (Relatório final - Processo n. ${ }^{\circ}$ 98/13371-5).

FERREIRA, G.C., DAITX, E.C. Características e especificações da areia industrial. Geociências, São Paulo, v.19, n.2, p.235242, 2000 b.

MARTIN, L., SUGUIO, K., FLEXOR, J.M., AZEVEDO, A.E.G. Mapa geológico do Quaternário Costeiro dos Estados do Paraná e Santa Catarina. Brasília: DNPM, 1988. 40p. (Série Geologia, 28, Seção Geologia Básica, 18).

\section{Artigo recebido em 09/12/2002 e} aprovado em 04/02/2002. 